\title{
Seismic Response Analysis of Reinforced Concrete Wall Structure Using Macro Model
}

\author{
Dong-Kwan Kim*
}

\author{
(Received January 10, 2016, Accepted February 5, 2016, Published online February 29, 2016)
}

\begin{abstract}
During earthquake, reinforced concrete walls show complicated post-yield behavior varying with shear span-to-depth ratio, re-bar detail, and loading condition. In the present study, a macro-model for the nonlinear analysis of multi-story wall structures was developed. To conveniently describe the coupled flexure-compression and shear responses, a reinforced concrete wall was idealized with longitudinal and diagonal uniaxial elements. Simplified cyclic material models were used to describe the cyclic behavior of concrete and re-bars. For verification, the proposed method was applied to various existing test specimens of isolated and coupled walls. The results showed that the predictions agreed well with the test results including the load-carrying capacity, deformation capacity, and failure mode. Further the proposed model was applied to an existing wall structure tested on a shaking table. Three-dimensional nonlinear time history analyses using the proposed model were performed for the test specimen. The time history responses of the proposed method agreed with the test results including the lateral displacements and base shear.
\end{abstract}

Keywords: nonlinear analysis, macro model, cyclic loads, earthquake loads, structural wall, reinforced concrete.

\section{Introduction}

Recently, nonlinear analysis has became popular in the earthquake design and evaluation of structures due to the advances in earthquake engineering and numerical analysis [ATC 40 (1996), FEMA 356 (ASCE 2000); FEMA 440 (ASCE 2005)]. In particular, reinforced concrete walls are used in many high-rise buildings as the primary lateral loadresistant system. Thus, an effective analytical method for walls is required to evaluate the overall inelastic response of buildings with walls. Both microscopic finite element models and macroscopic models can be used for the nonlinear analysis of wall systems. The microscopic finite element models can provide detailed local responses of walls with accuracy (Park and Klingner 1997; Okamura and Maekawa 1991; Stevens et al. 1991; Feenstra and de Borst 1993; Mansour and Hsu 2005; Wong and Vecchio 2002; Palermo and Vecchio 2007; Petrangeli et al. 1999; D’Ambrisi and Filippou 1999). However, it requires tremendous efforts and time for modeling and numerical computations. The macroscopic models, on the other hand, are simple and practical though their application is limited depending on the assumptions that each model is based on (Kabeyasawa et al. 1982; Vulcano and Bertero 1987; Orakcal 2004; Orakcal et al. 2006; Park and Eom 2007; Monti and Spacone 2000;

SEN Structural Engineers Co., R\&D Team, Seoul 07229, Korea.

*Corresponding Author; E-mail: dkkim@senkuzo.com Copyright ( $\odot$ The Author(s) 2016. This article is published with open access at Springerlink.com
Wallace 2012). Currently, because of the efficiency of the macroscopic models, existing structural analysis platforms such as Perform 3D (Computer and Structures Inc. 2006), OpenSEES (PEER 2001), and DRAIN-2DX (Prakash et al. 1993) use macroscopic models for the nonlinear analysis of wall systems.

Figure 1 shows various macroscopic models for the nonlinear analysis of walls subjected to cyclic loading. In Fig. 1, the existing macroscopic models use multiple vertical uniaxial elements of concrete and re-bar in order to describe the flexure-compression responses of walls such as the relocation of neutral axis in wall cross-sections, tension stiffening behavior of concrete, flexural crack opening and closing, and the confinement effect of the concrete in boundary elements. Previous studies (Vulcano and Bertero 1987; Orakcal 2004; Orakcal et al. 2006) show that the flexure-compression response of walls can be accurately predicted by using the existing macroscopic models. On the other hand, the existing macroscopic models use a horizontal uniaxial element (i.e. shear spring element) in order to describe the shear response of walls. However, the horizontal uniaxial element does not accurately describe the shear action associated with inclined cracking and diagonal strut action of the web concrete. Thus, it is difficult to accurately estimate the shear response of short and medium-rise wall, which is significantly affected by diagonal strut action.

In the present study, a macro finite element model was developed to predict the coupled flexure-compression and shear responses of the reinforced concrete walls subjected to cyclic loading. The macro-model was idealized with multiple longitudinal uniaxial elements of concrete and re-bar to describe the flexure- compression responses of walls. To describe the shear 


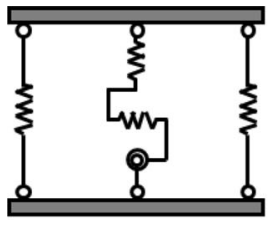

(a)

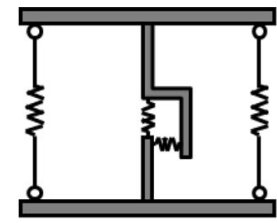

(b)

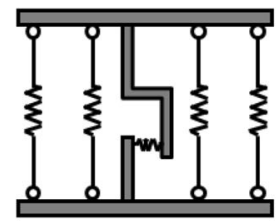

(c)

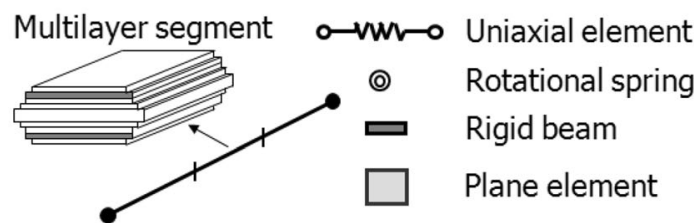

(d)

Fig. 1 Existing macro-models for structural walls. a Kabeyasawa et al. (1982), b Linda and Bachmann (1994), c Vulcano and Bertero (1987), d Monti and Spacone (2000).

response significantly affected by cyclic loading, diagonal strut elements were used. In the diagonal strut elements, for the web concrete, uniaxial cyclic models of concrete and steel re-bar were used. In the cyclic models, the confinement effect of concrete in wall boundary elements and the compressive softening of web concrete were considered. For verification, the proposed macro-model was applied to existing slender, lowrise, and coupled wall specimens subjected to cyclic loading. Further, the proposed macro-model was applied to three-dimensional nonlinear time history analysis for a 1:5 scale 10-story R.C. wall specimen of residential building specimen, which was tested on a shaking table.

\section{Proposed Macro-Model}

Figure 2 shows the proposed macro-model for walls. The proposed model consists of dimensionless lateral rigid beam elements, longitudinal uniaxial elements, diagonal uniaxial elements of concrete and re-bar. The longitudinal uniaxial elements of concrete and re-bar connecting the top and bottom rigid beams are used to describe the flexure-compression action of the wall. The plane section assumption was used by the top and bottom rigid beams. The diagonal elements of concrete are used to describe the shear response of the wall associated with the inclined cracking and strut action of the web concrete.

Each longitudinal element consists of concrete and re-bar, as shown in Fig. 2a. Perfect bond is assumed between the concrete and re-bar. Therefore, the concrete and re-bar have identical axial elongation or shortening due to the flexurecompression response of walls. The section areas $A_{l c}$ and $A_{l r}$ of the concrete and re-bar in a longitudinal element are defined with the tributary areas of the concrete and re-bars assigned to the longitudinal element at the wall cross-section (see Fig. 2b).

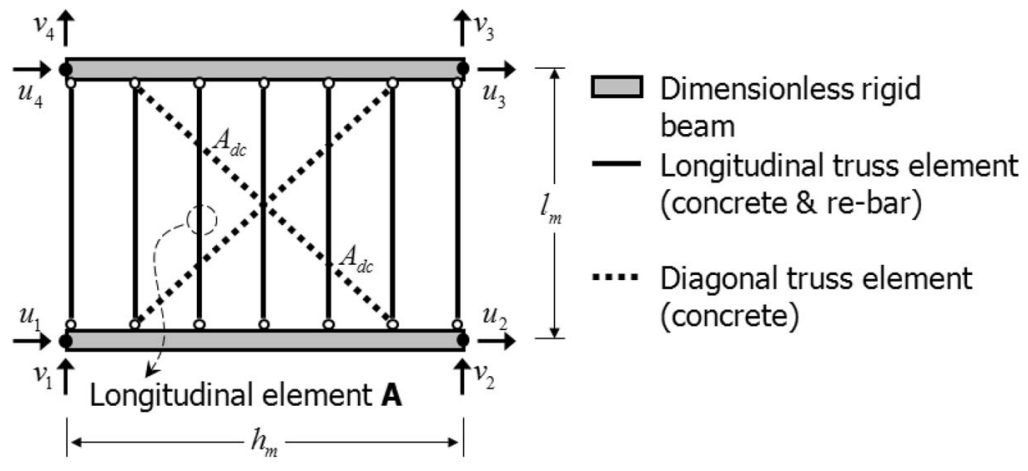

(a)

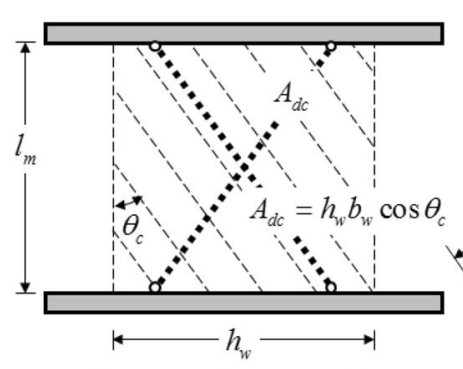

Single set of X-type diagonal concrete struts (c)

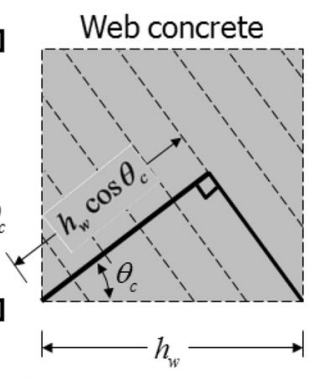

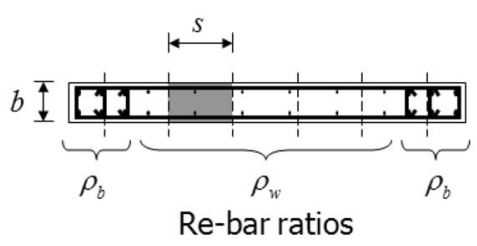

Tributary areas of longitudinal concrete and re-bar elements $\mathbf{A}$

$$
A_{l s}=\rho_{w} b s \quad A_{l c}=b s-A_{l s}
$$

(b)

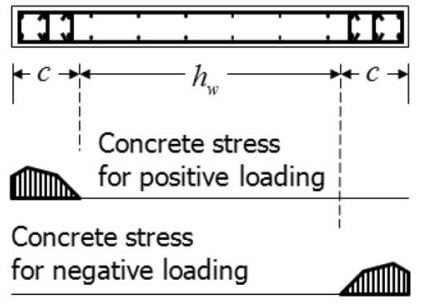

Definition of web depth $h_{w}$

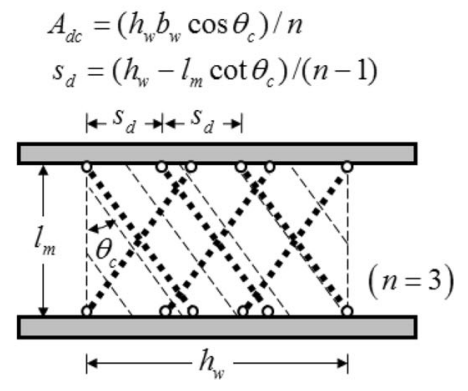

(d)

Fig. 2 Proposed macro-element for reinforced concrete wall. a Longitudinal-and-Diagonal-Line-Element-Model (LDLEM) element, b tributary areas of concrete and re-bar of each longitudinal uniaxial element, c diagonal concrete strut of wall web concrete, $\mathbf{d}$ multiple sets of X-type diagonal concrete struts. 


$$
\begin{aligned}
& A_{l c}=(1-\rho) b s \\
& A_{l r}=\rho b s
\end{aligned}
$$

where $b$ and $s$ are the width and depth of the wall crosssection segment assigned to a longitudinal element and $\rho$ is the longitudinal reinforcement ratio of the cross-section segment $b s$. The number of the longitudinal uniaxial elements can be increased to accurately describe the axial stress and strain distribution in the wall cross-section.

The diagonal element is defined with the concrete strut with an inclination angle of $\theta_{c}$, which is determined as the angle of the inclined cracking in the web concrete, as shown in Fig. 2c. Basically, the diagonal element is symmetrically arranged at the center of the web concrete. The section area $A_{d c}$ of the diagonal element is defined as the area of the web concrete transverse to the inclined cracking $\left(\theta_{c}\right)$ as follows.

$$
A_{d c}=b_{w} h_{w} \cos \theta_{c}
$$

where $b_{w}$ and $h_{w}$ are the width and depth of the web concrete. The depth $h_{w}$ of the web concrete is defined as the net tension zone depth of the wall cross section, which is calculated by subtracting the compression zone depths subjected to the positive and negative moments from the overall wall depth (see Fig. 2c). If a very high axial load is applied to a wall, the depth $h_{w}$ of the web concrete can be decreased to zero by definition, as shown in Fig. 2c. In such case, the proposed macro-model should not be used. If diagonal rebars with area $A_{d r}$ and inclination angle $\theta_{r}$ are used in the wall web, the diagonal uniaxial element of re-bar $\left(A_{d r}\right)$ can be added to the macro-element.

The height $l_{m}$ of a macro-element may significantly affect the overall response of walls, because the strains of longitudinal and diagonal uniaxial elements due to the flexurecompression and shear response of walls are assumed to be uniform over the height $l_{m}$. Thus, the height $l_{m}$ of the macroelement should be sufficiently small to accurately predict the flexure-compression response which is affected by the moment gradient along the wall height as well as the shear response influenced by the inclined cracking $\left(\theta_{c}\right)$ and strut action of the web concrete. Basically, $l_{m}$ should be smaller than $h_{w} \cot \theta_{c}$. If a refined wall model is required to address detailed response of the flexure-compression and shear actions, a smaller $l_{m}$ can be used.

For detailed shear response of short and medium-rise walls, multiple X-type diagonal uniaxial elements of concrete can be used, as shown in Fig. 2d. When $n$ sets of Xtype diagonal elements are used, the section area of each diagonal concrete element is determined as $b_{w} h_{w} \cos \theta_{c} / n$ and the spacing between the parallel diagonal concrete elements is $s_{d}=\left(h_{w}-l_{m} \tan \theta_{c}\right) /(n-1)$. In this case, the height $l_{m}$ of a macro-element should be smaller than $h_{w} \cot$ $\theta_{c} . l_{m}=h_{w} \cot \theta_{c} / n$ is recommended.

The depth $h_{w}$ of the web concrete can be determined by sectional analysis about the axial load applied to the wall, as shown in Fig. 2c. However, it is difficult to determine the depth $h_{w}$ of the web concrete in actual building structures without nonlinear analysis because the arrangement and cross-section shape of walls are complicate. In that case, $h_{w}$ can be approximately determined as follows. First, a trial $h_{w}$ which is less than the overall depth of the wall cross section is assumed to establish an initial macro-model. Nonlinear analysis is then performed for the wall model. If the compression zone of wall cross section resulting from the nonlinear analysis is located outside the assumed $h_{w}$, the assumed $h_{w}$ is acceptable. Otherwise, a smaller $h_{w}$ should be used, on the basis of the numerical analysis result.

The inelastic behavior of reinforced concrete walls are significantly affected by the inclined cracking angle $\theta_{c}$ of the web concrete. However, it is difficult to accurately estimate $\theta_{c}$ without sophisticated nonlinear numerical analysis because the web concrete is subjected to biaxial stresses. According to Oesterle et al. (1984), Vecchino and Collins (1986), and Bentz et al. (2006), the inclined cracking angle $\theta_{c}$ varies from 35 to $55^{\circ}$ depending on vertical and horizontal reinforcement ratios of the web concrete. In the present study, for convenience, $\theta_{c}=45^{\circ}$ is used for diagonal uniaxial elements of concrete. For more accurate analysis, the angle $\theta_{c}$ can be determined by using the modified compression field theory (Vecchino and Collins 1986; Bentz et al. 2006) or the softened truss model (Hsu and Mo 1985).

If shear reinforcement (i.e. horizontal reinforcement) is not sufficient, premature yielding of shear reinforcement occurs before flexural yielding of walls, which can increase the shear deformation of the wall under cyclic loading. However, the proposed macro-element cannot address the premature yielding of shear reinforcement since the dimensionless rigid beam elements restrain the tensile strain of shear reinforcement at the top and bottom of the macro-element. Therefore, the proposed method should be applied to the walls that have sufficient horizontal shear reinforcement.

The proposed macro-element can be easily incorporated into existing numerical analysis programs. Though a macroelement have a number of uniaxial elements of concrete and re-bar, the number of degree-of-freedoms of a macro-element can be reduced to a rectangular element with only 6 degree-of-freedoms $\left(u_{1}, u_{4}, v_{1}, v_{2}, v_{3}\right.$, and $v_{4}$, see Fig. $\left.2 \mathrm{a}\right)$ by static condensation. Thus, the number of degree-of-freedoms can be significantly reduced, which save time and efforts in modeling and numerical computations.

In the present study, it was assumed that the shear force was carried by the non-flexural area (grey area in Fig. 4), which was determined by the longitudinal reinforcement ratio. Also the diagonal elements, which affect the lateral stiffness of the wall, were determined by the non-flexural area. This indicates that the lateral stiffness of the wall can be easily simulated by the geometry and the longitudinal reinforcement ratio of the wall.

\section{Material Models of Concrete and Re-bar}

The cyclic stress-strain relationship of concrete developed by Chang and Mander (1994) was used for uniaxial concrete elements of the proposed macro-element. In Fig. 3a, three 


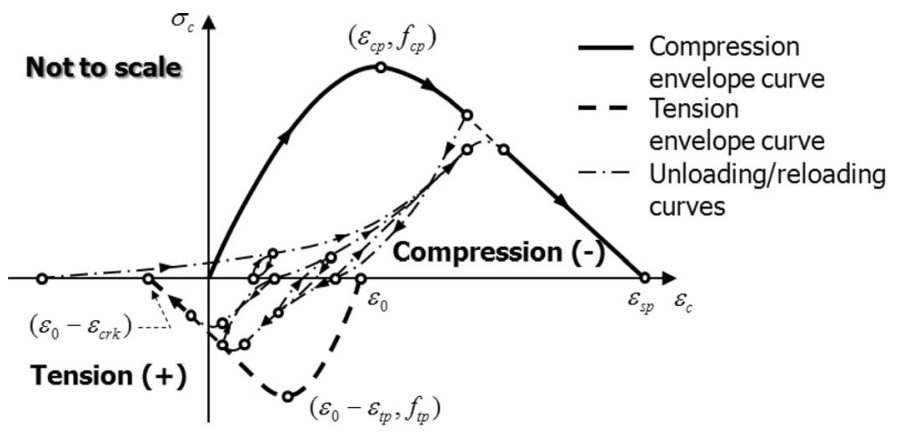

(a)

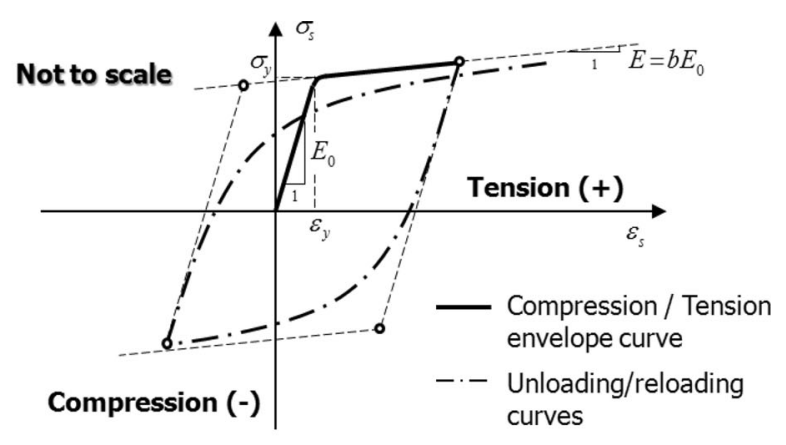

(b)

Fig. 3 Cyclic stress-strain relationships of concrete and re-bar uniaxial elements. a Cyclic model for concrete (Chang and Mander's model), b cyclic model for re-bar (Menegotto and Pinto's model).

types of curves are used to describe the cyclic stress-strain relationship: the compressive envelope curve, the tensile envelope curve, and the unloading/reloading curve connecting smoothly the two envelope curves. Basically, the Chang and Mander's concrete model is defined by the initial modulus of elasticity $\left(E_{c}\right)$, stress and strain at the compression peak strength $\left(f_{c p}\right.$ and $\left.\varepsilon_{c p}\right)$, post-crushing strain at zero compression stress $\left(\varepsilon_{s p}\right)$, stress and strain $\left(f_{t p}\right.$ and $\left.\varepsilon_{t p}\right)$ at the tension peak strength, and post-tensile cracking strain at zero tensile stress $\left(\varepsilon_{c r k}\right)$ (see Fig. 3a). Detailed equations defining the stress-strain relationship can be found in the relevant reference (Chang and Mander 1994).

For longitudinal concrete elements, the compressive stresses and strains are defined as $f_{c p}=f_{c}^{\prime}, \varepsilon_{c p}=\varepsilon_{c o}$, and $\varepsilon_{s p}=\varepsilon_{c u} . f_{c}^{\prime}$ is the compressive strength, $\varepsilon_{c o}$ is the strain corresponding to $f_{c}^{\prime}$, and $\varepsilon_{c u}\left(=2 \varepsilon_{c o}\right.$, Zhang and Hsu 1998) is the ultimate strain. When concrete is confined by lateral reinforcement, the compressive strength and deformation capacity are increased. In this case, the increased material properties $f_{c c}, \varepsilon_{c c o}$, and $\varepsilon_{c c u}$ of the confined concrete replace $f_{c p}, \varepsilon_{c p}$, and $\varepsilon_{s p}$, respectively (Mander et al. 1988).

$$
\begin{aligned}
& f_{c c}=K f_{c}^{\prime} \\
& \varepsilon_{c c o}=-0.002(1+5(K-1)) \\
& \varepsilon_{c c u}=-0.012 \\
& K=-1.254+2.254 \sqrt{1+7.94 f_{l}^{\prime} / f_{c}^{\prime}}-2 f_{l}^{\prime} / f_{c}^{\prime}
\end{aligned}
$$

where $f_{l}^{\prime}$ is the effective confining stress due to the lateral confinement reinforcement. $f_{l}^{\prime}$ can be determined based on the volumetric ratio and yield stress of the confinement reinforcement (Mander et al. 1988). The tensile stresses and strains in the Chang and Mander's model are defined as $f_{t p}=0.31 \sqrt{f_{c}^{\prime}}$ (Zhang and Hsu 1998), $\varepsilon_{t p}=f_{t p} / E_{c}$, and $\varepsilon_{c r k}=2 \varepsilon_{t p}$.

For diagonal concrete elements, the compressive strength of concrete was defined considering the effect of coexisting diagonal cracking: when inclined cracking occurs in the web concrete, the compressive strength of the web concrete decreases (Vecchino and Collins 1986; Zhang and Hsu
1998). According to Vecchino and Collins (1986), the effective compressive strength of a concrete strut is defined as a function of the transverse tensile strain $\varepsilon_{t}$ orthogonal to the concrete strut.

$$
f_{c e}=\frac{f_{c}^{\prime}}{0.8-0.34 \varepsilon_{t} / \varepsilon_{c o}} \leq f_{c}^{\prime}
$$

As shown in Fig. 4, the transverse tensile strain $\varepsilon_{t}$ can be calculated by using horizontal and vertical displacements of a virtual four-node plane element enclosing the diagonal concrete element as follows.

$$
\varepsilon_{t}=\varepsilon_{y} \sin ^{2} \theta_{c}+\gamma \cos \theta_{c} \sin \theta_{c}
$$

where,

$$
\begin{aligned}
\varepsilon_{y} & =\frac{\left(v_{4}-v_{1}\right)+\left(v_{3}-v_{2}\right)}{2 l_{m}} \text { and } \gamma \\
& =\frac{\left(u_{4}-u_{1}\right)}{l_{m}}+\frac{\left(v_{4}-v_{1}\right)+\left(v_{3}-v_{2}\right)}{2 h_{w}}
\end{aligned}
$$

In Eqs. (6) and (7), $u_{1}, u_{4}, v_{1}, v_{2}, v_{3}$, and $v_{4}$ are the horizontal and vertical displacements of the virtual four-node plane element; $\varepsilon_{y}$ and $\gamma$ are the mean vertical strain and shear strain of the virtual plane element (see Fig. 4). Note that the horizontal strain $\varepsilon_{x}$ of the virtual plane element is zero because the dimensionless rigid beam elements at the top and bottom of the macro-element restrain the horizontal expansion due to shear.

In the proposed method, web concrete crushing is assumed to occur when the compressive stress of the diagonal concrete element is greater than the effective compressive strength $f_{c e}$ calculated by Eq. (3).

For the longitudinal and diagonal uniaxial re-bar elements, the Menegotto and Pinto's model addressing tension stiffening effect and the Bauschinger effect was used (Menegotto and Pinto 1973). As shown in Fig. 3b, two slopes $E_{s}$ and $b E_{s}$ are used to define the nonlinear stress-strain relationship of re-bars under cyclic loading ( $E_{s}=$ the modulus of elasticity of re-bar; and $b=$ the strain hardening ratio). Further details of the Menegotto and Pinto's model can be found in the reference (Menegotto and Pinto 1973). 


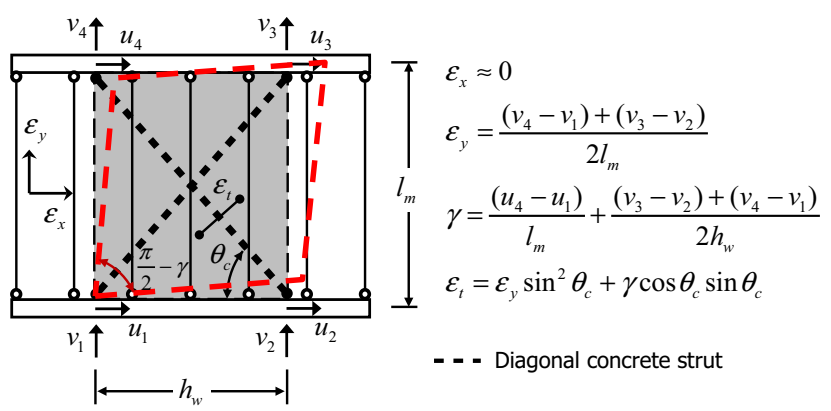

Fig. 4 Transverse tensile strain orthogonal to diagonal concrete strut.

\section{Verification of Proposed Model}

For verification, the proposed macro-model was applied to existing isolated and coupled wall specimens subjected to cyclic loading. Table 1 shows the material and geometric properties of the wall specimens. For nonlinear analysis, a computer program for structural analysis, OpenSEES, was used OpenSEES (PEER 2001). The OpenSEES material models, Concrete07 and Steel02, are the same as the concrete and re-bar models of Sect. 3. Therefore, Concrete07 and Steel02 were used for the longitudinal and diagonal uniaxial elements of the macro-element (OpenSEES PEER 2001).

\subsection{Slender Walls}

Figure 5a shows the reinforcement details and geometric properties of slender wall specimens RW2 and TW2 (Thomsen and Wallace 2004). The shear span length and the overall depth of the cross section were $l=3810 \mathrm{~mm}$ and $h=1219 \mathrm{~mm}$, respectively (shear span-to-depth ratio $l / h=3.13)$. RW2 with rectangular cross section and TW2 with T-shaped cross section were subjected to axial compression loads $=0.07 A_{g} f_{c}^{\prime}$ and $0.075 A_{g} f_{c}^{\prime}$, respectively, where $A_{g}$ is the gross area of cross section. Due to the large shear span-to-depth ratio and the axial compression loads, the cyclic behavior of RW2 and TW2 was dominated by flexure-compression (Thomsen and Wallace 2004). The compressive strength of concrete was $f_{c}^{\prime}=34.0 \mathrm{MPa}$ for RW2 and 41.7 MPa for TW2. The yield stress of re-bars was $f_{y}=414 \mathrm{MPa}$. Reinforcement details of RW2 and TW2 are presented in detail in Thomsen and Wallace (2004) and Massone and Wallace (2009).

Figure $5 \mathrm{~b}$ shows the macro-models of RW2 and TW2 for nonlinear analysis. RW2 and TW2 were idealized with five macro-elements $\left(l_{m}=762 \mathrm{~mm} \leq h_{w} \cot \theta_{c}\right)$. Each macroelement consisted of eight longitudinal uniaxial elements of concrete and re-bar (L1 and L2). A set of X-type diagonal uniaxial concrete elements $\left(\mathbf{D}, \theta_{c}=45^{\circ}\right)$ was located at the center of the wall web. The section areas of the concrete and rebar elements are presented in Fig. 5b. The concrete confined with hoops and cross ties were represented as the shaded areas at the cross sections, as shown in Fig. 5a. Since the end zone of the cross sections of RW2 and TW2 included confined and unconfined concretes, the confined and unconfined concretes were separately considered as the section areas $A_{l c c}$ and $A_{l c}$ (see $\mathbf{L 1}$ element of Fig. 5b). The section area of the diagonal concrete element D was calculated using $h_{w}=1019 \mathrm{~mm}$ for RW2 and $889 \mathrm{~mm}$ for TW2. The depths $h_{w}$ of web concrete in RW2 and TW2 were estimated from sectional analysis using the actual material strengths [see Eq. (3)].

Figure 5c compares the lateral load-drift ratio relationships of RW2 and TW2 resulting from the macro-model analysis and the test. In the case of RW2 with rectangular

Table 1 Dimensions and properties of existing wall specimens.

\begin{tabular}{|c|c|c|c|c|c|c|c|}
\hline Specimens & Cross section & $f_{c}^{\prime}(\mathrm{MPa})$ & $f_{y}(\mathrm{MPa})$ & $A_{s} / A_{S}^{\prime}\left(\mathrm{mm}^{2}\right)$ & $A_{w}\left(\mathrm{~mm}^{2}\right)$ & $d(\mathrm{~mm})$ & $P /\left(A_{g} f_{c}^{\prime}\right)(\%)$ \\
\hline \multicolumn{8}{|c|}{ Thomsen 2004} \\
\hline RW2 & Rectangular & 34.0 & 448 & $570 / 570$ & 253 & 1200 & 7.0 \\
\hline TW2 & T-Shaped & 41.7 & 448 & $1965 / 713$ & 253 & 1200 & 7.5 \\
\hline \multicolumn{8}{|c|}{ Salonikios 1999} \\
\hline MSW2 & Rectangular & 26.2 & 585 & $301 / 301$ & 193 & 1100 & 0.0 \\
\hline MSW3 & & 24.1 & 585 & $301 / 301$ & 193 & 1100 & 7.0 \\
\hline \multicolumn{8}{|c|}{ Sittipunt 2001} \\
\hline W1 & Barbell-type & 36.6 & 390 & $1432 / 1432$ & 392 & 1300 & 0.0 \\
\hline W2 & & 35.8 & 390 & $1432 / 1432$ & 549 & 1300 & 0.0 \\
\hline \multicolumn{8}{|c|}{ Massone 2009} \\
\hline Test1 & Rectangular & 25.5 & 424 & $804 / 804$ & 796 & 1456 & 0.0 \\
\hline Test6 & & 31.4 & 424 & $258 / 258$ & 398 & 1456 & 10.0 \\
\hline \multicolumn{8}{|c|}{ Lee 2010} \\
\hline RCSW & T-shaped & 23.3 & 552 & $942 / 942$ & 2984 & 1555 & 0.0 \\
\hline RCSW-B & & 23.5 & 552 & $942 / 942$ & 2984 & 1555 & 0.0 \\
\hline
\end{tabular}




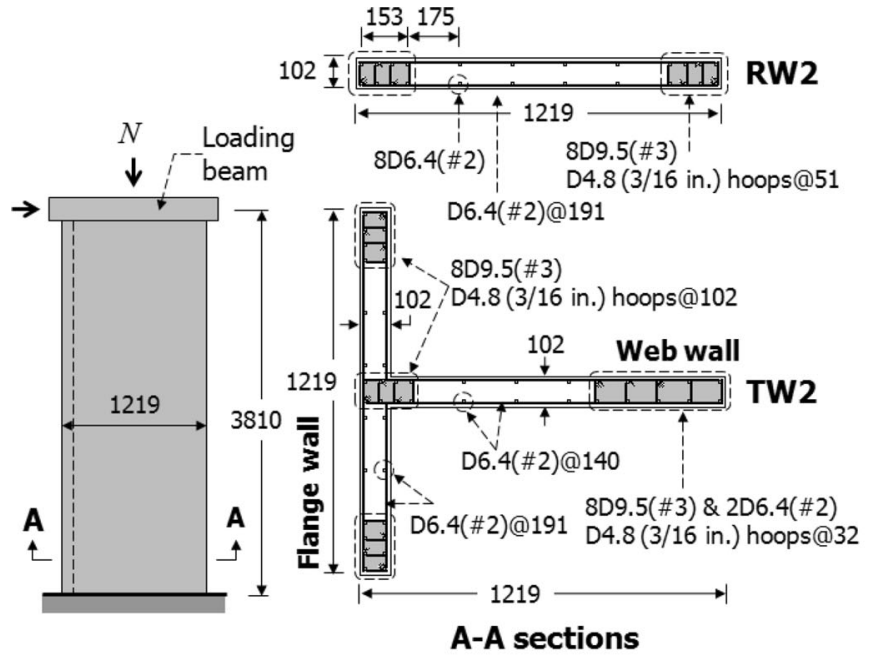

(a)

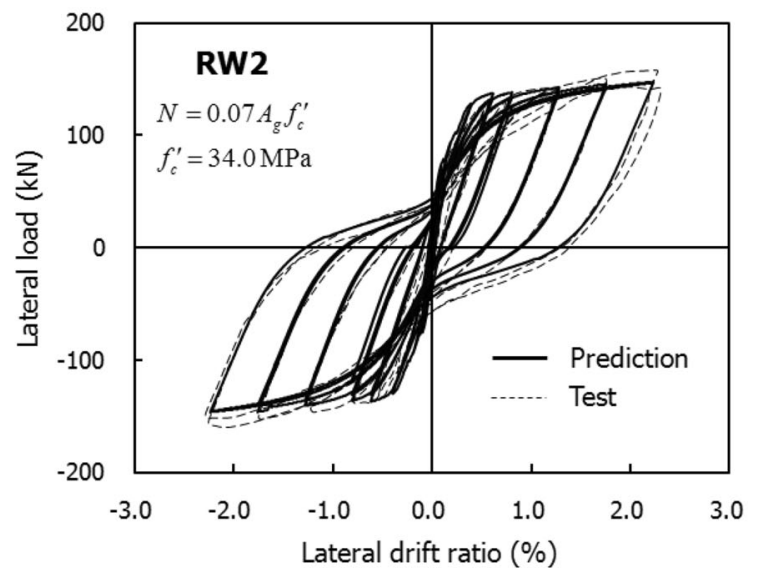

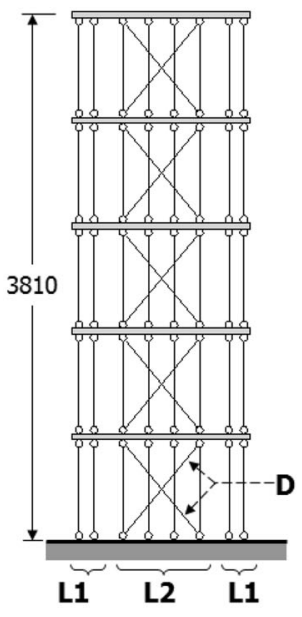

\begin{tabular}{c|c|c|c}
\hline \multicolumn{2}{c|}{ Uniaxial elements } & RW2 & TW2 \\
\hline \multirow{4}{*}{ L1 } & $A_{l c c}\left(f_{c c}\right)$ & $6400(39)$ & $32648(47)$ \\
\cline { 2 - 4 } & $A_{l c}$ & 3341 & 91690 \\
\cline { 2 - 4 } & $A_{l s}(\mathrm{D} 10 / \mathrm{D} 6)$ & $284 / 0$ & $1420 / 248$ \\
\hline \multirow{2}{*}{$\mathbf{L 2}$} & $A_{l c}$ & 17850 & 17850 \\
\cline { 2 - 4 } & $A_{l s}(\mathrm{D} 6)$ & 62 & 62 \\
\hline D & $A_{d c}$ & 73495 & 64119 \\
\hline
\end{tabular}

$A_{l \infty}$ Area of confined concrete $\left(\mathrm{mm}^{2}\right)$

$A_{l c}$ Area of unconfined concrete $\left(\mathrm{mm}^{2}\right)$

$A_{k}$ Area of re-bars $\left(\mathrm{mm}^{2}\right)$

$A_{c c}$ Area of diagonal concrete strut $\left(\mathrm{mm}^{2}\right)$

$f_{c c}$ Compressive strength of confined $f_{c}$ concrete (MPa)

(b)

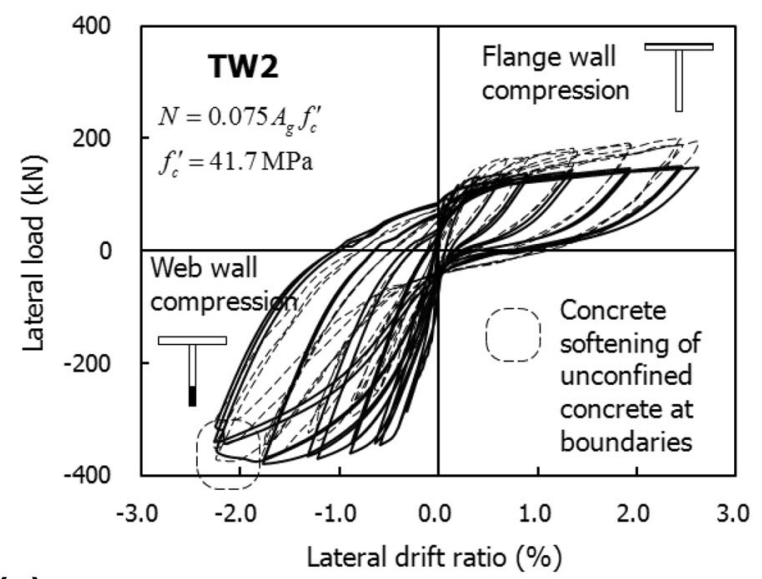

(c)

Fig. 5 Slender wall specimens RW2 and TW2 (Thomsen and Wallace 2004). a Dimensions and re-bar details (mm), b LDLEM modelling of wall specimens, c comparison of LDLEM analysis and test results.

cross section, the proposed method accurately predicted well the initial stiffness, load-carrying capacity, and unloading/ reloading behaviors during cyclic loading. The flexural pinching caused by axial compression load was also predicted well. On the other hand, for TW2 with T-shaped cross section, the load-carrying capacity and initial stiffness were slightly overestimated under the negative loading in which the flange wall was in compression (see Fig. 5c). This is because TW2 with T-shaped cross section was idealized with the two-dimensional macro-elements; therefore, the shearlag behavior of the flange wall in the vertical direction could not be addressed (see Fig. 5a).

In the test, TW2 failed due to the compressive softening of the concrete and the subsequent spalling of the cover concrete (see dotted lines in Fig. 5c). On the other hand, web concrete crushing did not occur in RW2 and TW2 because the axial compression load restrained the transverse tensile strain $\varepsilon_{t}$ of the web concrete. The failure mode of the numerical analysis correlated with the test results.

\subsection{Low-Rise Walls}

The proposed method was applied to low-rise wall specimens, MSW2 and MSW3 (Salonikios et al. 1999, 2000). In Fig. 6a, the shear span length and the overall depth of cross section were $l=1800 \mathrm{~mm}$ and $h=1200 \mathrm{~mm}$, respectively $(l / h=1.50)$. Both MSW2 and MSW3 had rectangular cross sections with confined end zones. No axial compression load was applied to MSW2. Small axial force, $N=0.07 A_{g} f_{c}^{\prime}$ $(=210 \mathrm{kN})$ was applied to MSW3. The concrete strength was $f_{c}^{\prime}=26.2 \mathrm{MPa}$ for MSW2 and 24.1 MPa for MSW3. The yield stress was $f_{y}=585 \mathrm{MPa}$ for D8 bars and $610 \mathrm{MPa}$ for D4 bars. The reinforcement details, geometric properties, and material properties are presented in Salonikios et al. (1999, 2000).

Figure $6 \mathrm{~b}$ shows the macro-models. Four macro-elements were used for each wall specimen $\left(l_{m}=450 \mathrm{~mm} \approx\left(h_{w} \cot \right.\right.$ $\left.\left.\theta_{c}\right) / n\right)$. Seventeen longitudinal uniaxial elements of concrete and re-bar were used for each macro-element. For the longitudinal element $\mathbf{L} \mathbf{1}$ in the end zones of the cross sections, 


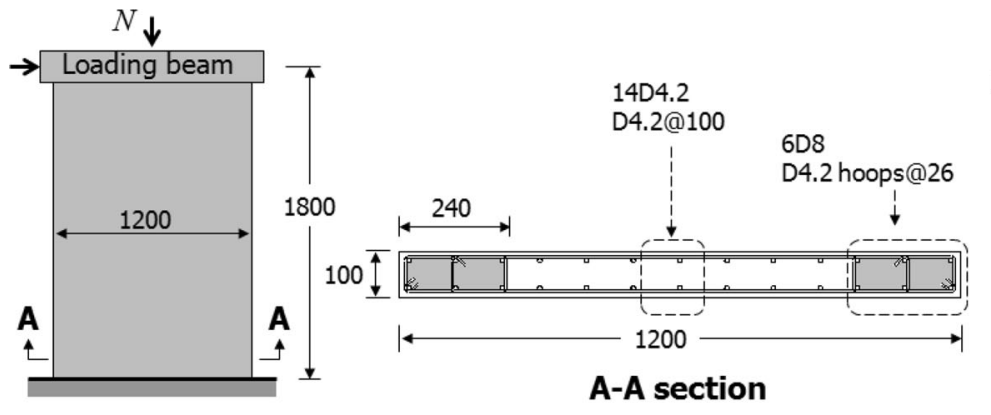

(a)
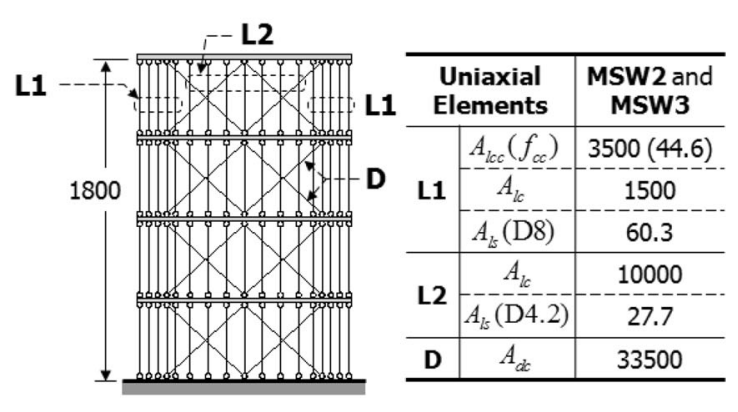

(b)

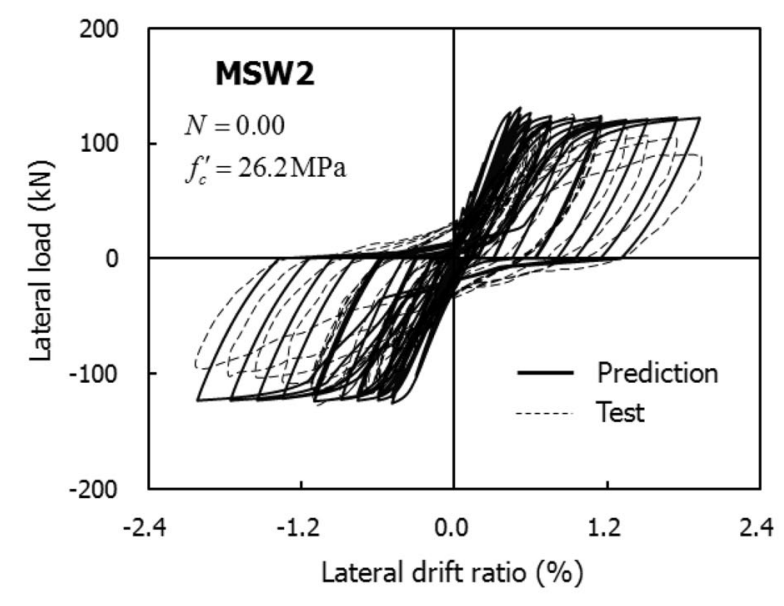

(c)

Fig. 6 Low-rise wall specimens MSW2 and MSW3 (Salonikios et al. 1999). a Dimensions and re-bar details (mm), b analysis model and element areas $\left(\mathrm{mm}^{2}, \mathrm{MPa}\right), \mathbf{c}$ comparison of LDLEM analysis and test results.

the confined and unconfined concretes were considered (see Fig. 6b). To accurately evaluate the shear response of the wall specimens, two sets of X-type diagonal concrete elements $\mathrm{D}$ were used for each macro-element $\left(\theta_{c}=45^{\circ}\right.$; $h_{w}=948 \mathrm{~mm}$ for MSW2 and MSW3; and $\left.n=2\right)$. The section areas of concrete and re-bar of the longitudinal and diagonal elements are presented in Fig. 6b.

Figure 6c compares the lateral load-drift ratio relationships predicted by the proposed method with the test results. In MSW2 without no axial compression load, pinching and shear-slip deformation were significant in the cyclic response. On the other hand, in MSW3 subjected to axial compression load $N=0.07 A_{g} f_{c}^{\prime}$, the pinching and shear-slip deformation were decreased as the axial compression load restrained inclined diagonal cracking in the web. As shown in Fig. 6c, the proposed method predicted the shear responses of MSW2 and MSW3 with reasonable precision. Ultimately, strength degradation due to softening of the unconfined cover concrete occurred in MSW2 (see dashed line in Fig. 6c). However, the proposed method did not properly capture such strength degradation (see solid line in Fig. 6c). In MSW3 subjected to $N=0.07 A_{g} f_{c}^{\prime}$, the loadcarrying capacity was decreased due to the second-order effect and softening of the unconfined cover concrete. The analysis results correlated well with the test results. Web concrete crushing didn't occur in both specimens. Neither the test nor the proposed method predicted the web concrete crushing failure of MSW2 and MSW3.

The proposed method was applied to wall specimens W1 and W2 with barbell-shaped cross sections (Sittipunt et al. 2001). As shown in Fig. 7a, the shear span length and the overall depth of cross section were $l=2150 \mathrm{~mm}$ $(=1900+500 / 2 \mathrm{~mm})$ and $h=1500 \mathrm{~mm}$, respectively $(l / h=1.43)$. Figure $7 \mathrm{~b}$ shows the macro-models. Three macro-elements were used for each wall specimen. Thirteen longitudinal elements of concrete and re-bar and two sets of X-type diagonal elements of concrete were used for each macro-element $\left(\theta_{c}=45^{\circ} ; h_{w}=1252 \mathrm{~mm}\right.$ for $\mathrm{W} 1$ and $1366 \mathrm{~mm}$ for $\mathrm{W} 2$; and $n=2)$. The concrete strength was $f_{c}^{\prime}=36.6 \mathrm{MPa}$ for $\mathrm{W} 1$ and $35.8 \mathrm{MPa}$ for $\mathrm{W} 2$. The yield stress of re-bar was $f_{y}=473 \mathrm{MPa}$ for D16 bars, $425 \mathrm{MPa}$ for D12 bars, and $450 \mathrm{MPa}$ for D10 bars. The vertical and horizontal reinforcement ratios were $\rho_{v}=0.0052$ and $\rho_{h}=0.0039$ for $\mathrm{W} 1$ and $\rho_{v}=0.0079$ and $\rho_{h}=0.0052$ for $\mathrm{W} 2$.

Figure 7c compares the lateral load-drift ratio relationships of W1 and W2 predicted by the proposed method with the test results. The solid and dashed lines indicate the predictions and the test results, respectively. When compared to MSW2 and MSW3, W1 and W2 showed significant shear-slip deformation and pinching in the cyclic responses. As shown in Fig. 7c, the proposed method predicted the 


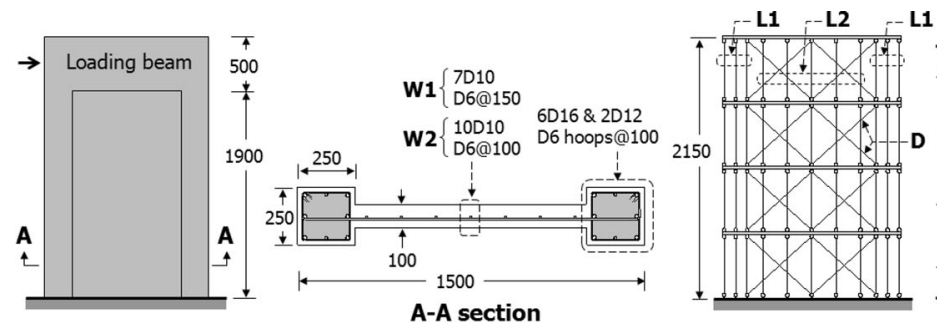

(a)

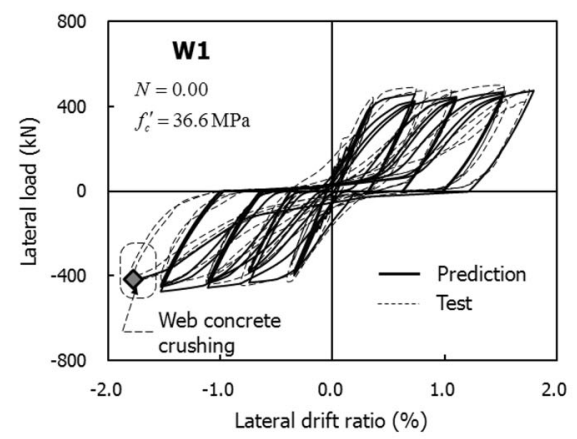

(c)

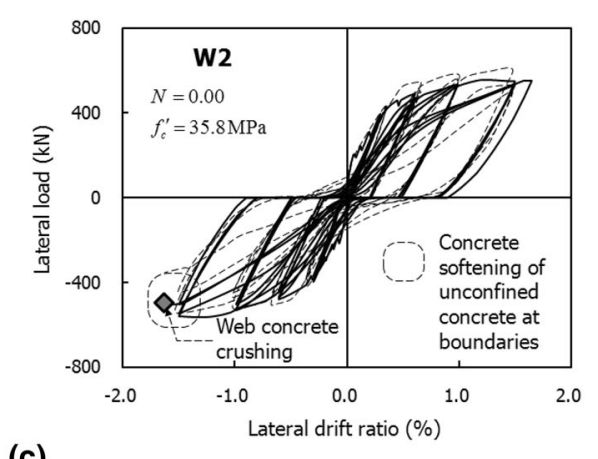

Fig. 7 Low-rise wall specimens W1 and W2 with barbell-shaped cross section (Sittipunt et al. 2001). a Dimensions and re-bar details $(\mathrm{mm}), \mathbf{b}$ analysis model and element areas $\left(\mathrm{mm}^{2}, \mathrm{MPa}\right), \mathbf{c}$ comparison of LDLEM analysis and test results.

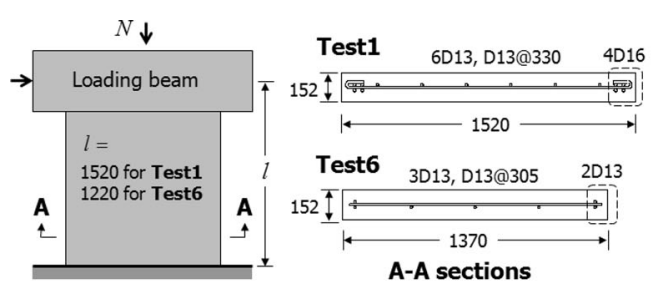

(a)

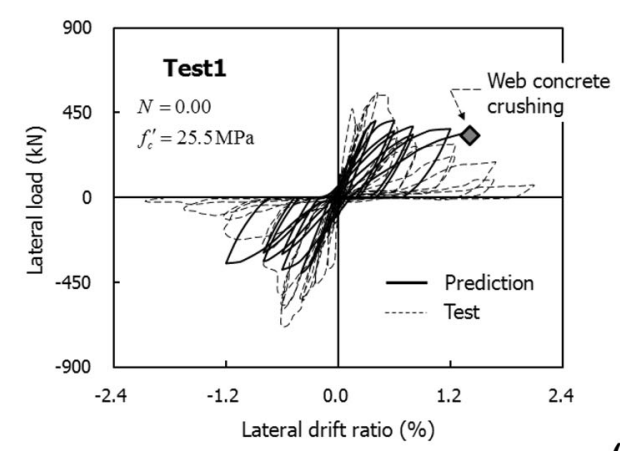

(c)

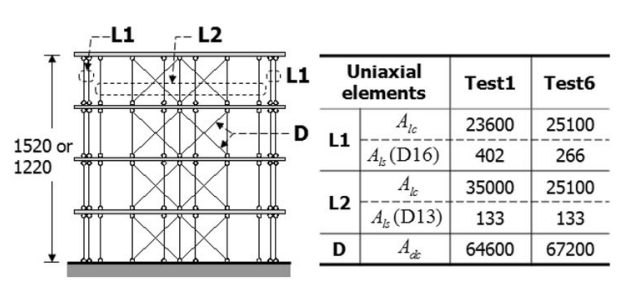

(b)

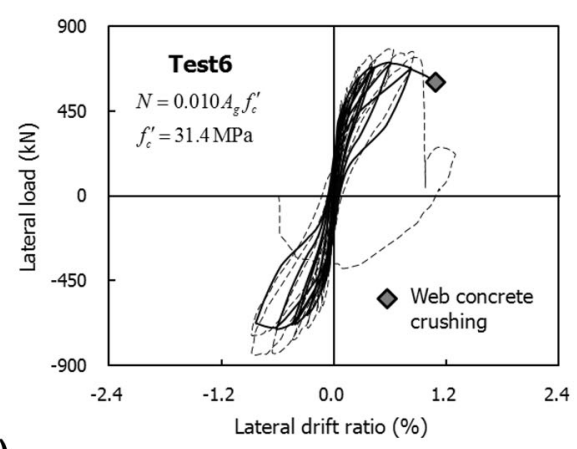

Fig. 8 Squat wall specimens Test1 and Test6 (Massone et al. 2009). a Dimensions and re-bar details (mm), b analysis model and element areas, c comparison of LDLEM analysis and test results.

shear responses of $\mathrm{W} 1$ and $\mathrm{W} 2$ with reasonable precision. The numerical analysis predicted web crushing of diagonal element D at lateral drift ratios $-1.80 \%$ (W1) and $-1.70 \%$ (W2) (see grey diamond remarks in Fig. 7). The predicted failure modes agree with the test results.

\subsection{Squat Walls}

The proposed method was applied to squat wall specimens Test1 and Test6 (Massone et al. 2009). In Fig. 8a, the shear span length and the overall depth of the cross section were $l=1520 \mathrm{~mm}$ and $h=1520 \mathrm{~mm}$ for Test $1(l / h=1.00)$ and $l=1220 \mathrm{~mm}$ and $h=1370 \mathrm{~mm}$ for Test6 $(l / h=0.89)$. Test6 was subjected to a moderate axial compression load $N=0.10 A_{g} f_{c}^{\prime}$, while Test1 was not subjected to axial compression load $(N=0)$. The concrete strength was $f_{c}^{\prime}=25.5 \mathrm{MPa}$ for Test1 and 31.4 MPa for Test6. The yield stress was $f_{y}=448 \mathrm{MPa}$ for D16 bars and $427 \mathrm{MPa}$ for D13 bars.

Figure $8 \mathrm{~b}$ shows the macro-models of Test1 and Test6. Four macro-elements were used for each wall specimen. 


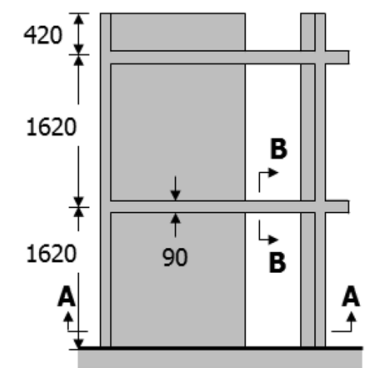

T-shaped wall Wall-column

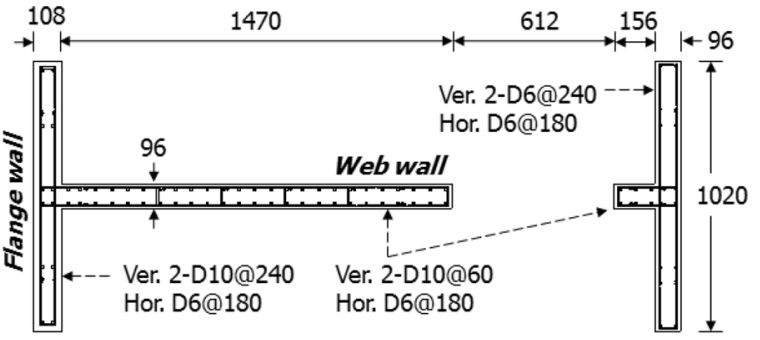

T-shaped wall
Wall-column

A-A section

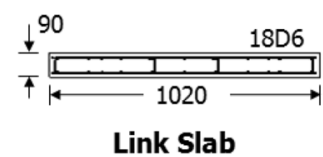

B-B section

(a)

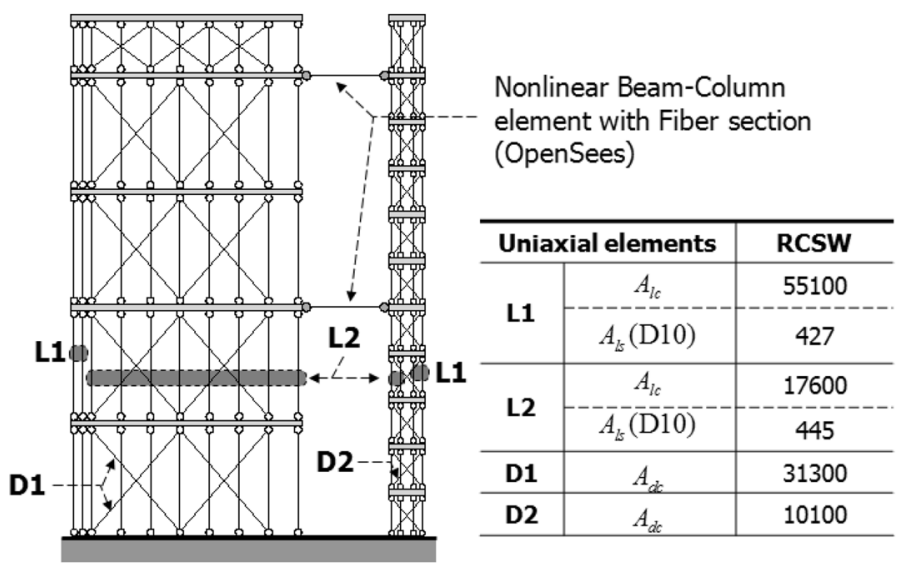

(b)

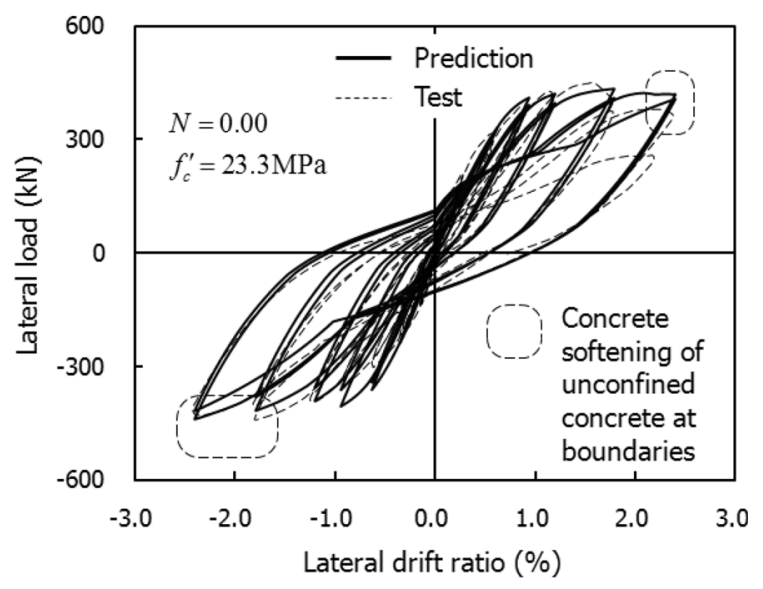

(c)

Fig. 9 Coupled wall specimens RCSW (Lee et al. 2010). a Dimensions and re-bar details (mm), b analysis model and element areas, c comparison of LDLEM analysis and test results.

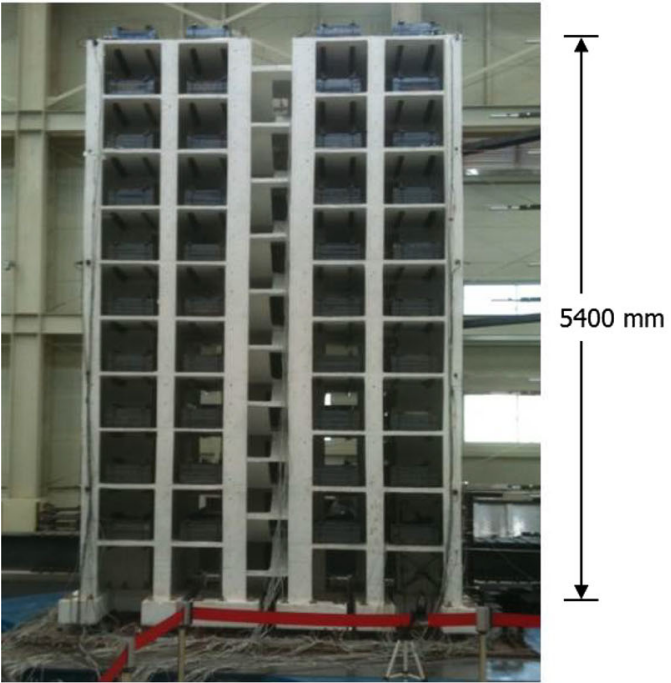

(a)

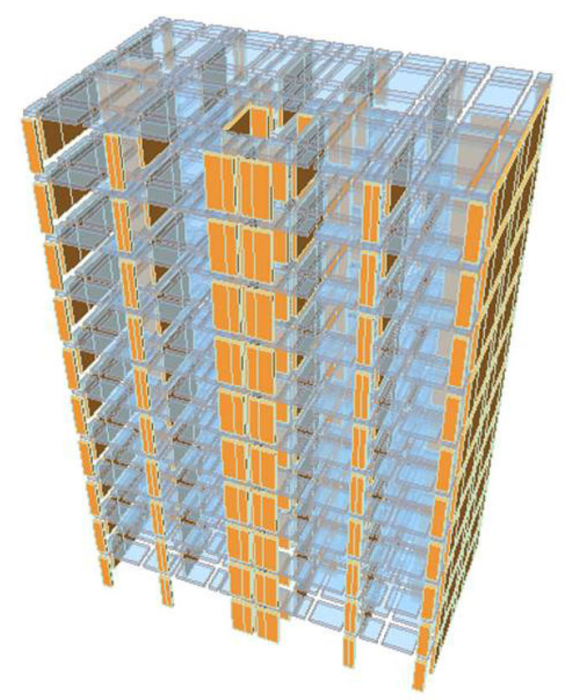

(b)

Fig. 10 3-Dimesional 1/5 scale RC wall building model and analysis model. a 1/5 scale test model, b scheme of analysis model.

Eleven longitudinal elements of concrete and re-bar were used for each macro-element. For the shear response of the squat wall specimens, two sets of X-type diagonal elements D were used for each macro-element $\left(\theta_{c}=45^{\circ}\right.$; $h_{w}=1202 \mathrm{~mm}$ for Testl and $h_{w}=1251 \mathrm{~mm}$ for Test6; and $n=2)$. The section areas of concrete and re-bar of the longitudinal and diagonal elements are presented in Fig. 8b.
Figure 8c compares the lateral load-drift ratio relationships predicted by the proposed method with the test results. Although the proposed method predicted well the pinching and web concrete crushing in the cyclic responses varying with the axial compression load, the load-carrying capacities of Test1 and Test6 were underestimated. 


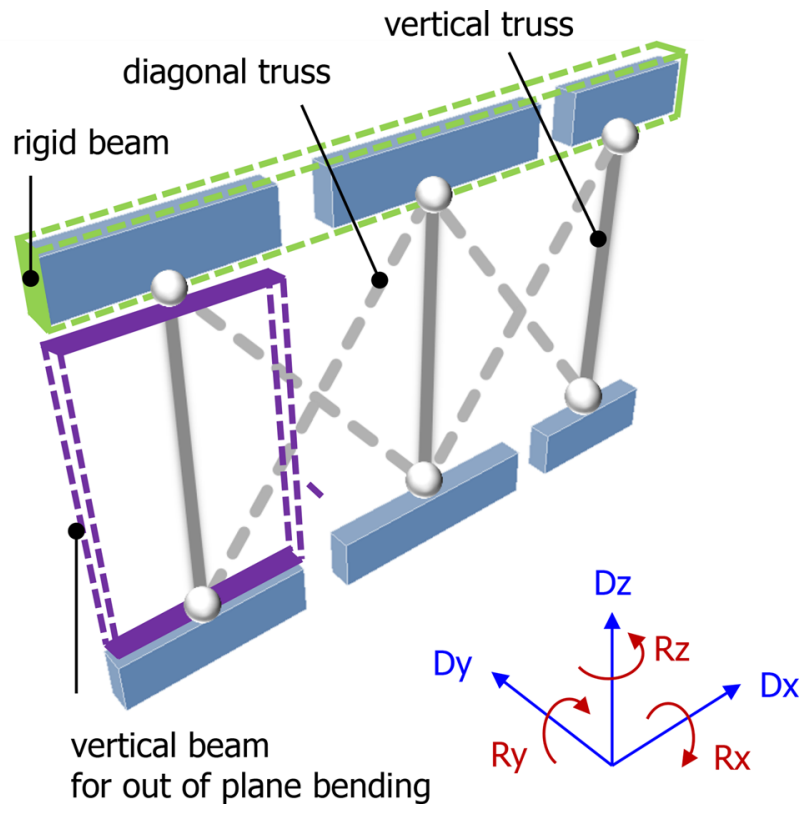

Fig. 11 Unit model for 3-D wall building.

\subsection{Coupled Walls}

The proposed method was applied to a coupled wall specimen RCSW (Lee et al. 2010). Figure 9a shows the configurations, cross sections, and reinforcement details of RCSW. RCSW consisted of a T-shaped wall, a wall-column, and slabs (see Fig. 9a). The wall and wall-column were connected by the link slabs (thickness $=90 \mathrm{~mm}$ ). The shear span of RCSW was $l=3910 \mathrm{~mm}$. The total depth of the cross section including the T-shaped wall, wall-column, and opening was $h=2442 \mathrm{~mm}$. The concrete strength was $f_{c}^{\prime}=23.3 \mathrm{MPa}$. The yield stress of re-bars was $f_{y}=553 \mathrm{MPa}$ for D10 bars and $340 \mathrm{MPa}$ for D6 bars. The hoop re-bars for concrete confinement were not used in the T-shaped wall and wall-column (see Fig. 9a).
Figure 9b shows the macro-model. The T-shaped wall and wall-column were modeled with five and eleven macroelements, respectively. In the T-shaped wall, ten longitudinal elements (L1 and L2) of concrete and re-bar were used for each macro-element. Since the cyclic response of the T-shaped wall was expected to be dominated by shear, two sets of X-type diagonal elements (D1, $\left.h_{w}=922 \mathrm{~mm}\right)$ of concrete were used. On the other hand, for the wall-column which was dominated by flexure-compression, four longitudinal elements (L1 and L2) and a set of X-type diagonal elements (D2, $\left.h_{w}=149 \mathrm{~mm}\right)$ were used. The link slabs (thickness $=90 \mathrm{~mm}$ ) which are dominated by flexural action were modeled with equivalent beam elements (nonlinear Beam-Column Element of OpenSEES (PEER 2001) with fiber section).

Figure 9c compares the lateral load-drift ratio relationship. The solid and dashed lines indicate the prediction and the test result, respectively. The proposed method accurately predicted the overall cyclic responses. As shown in Fig. 9c, at a lateral drift ratio of $1.7 \%$, compression softening and subsequent spalling of the unconfined cover concrete occurred at the boundary of the web wall in the T-shaped wall. The failure mode agreed with the test result.

\subsection{Shaking Table Test for Wall-Slab Structure}

Lee et al. (2011) reported results of a shaking table test on a 1:5 scale 10-story R.C. wall specimen of a residential building. Using the proposed macro-model, three-dimensional nonlinear time history analyses were performed. The predicted results were compared with the test result.

Figure 10a shows the test specimen. The external dimensions of the specimen were $3560 \mathrm{~mm} \times 2220 \mathrm{~mm} \times$ $5400 \mathrm{~mm}$ (x-length $\times$ y-length $\times$ height $)$. The thicknesses of the exterior wall, interior wall, and slab were 36,32 , and $40 \mathrm{~mm}$, respectively. In the wall, $3 \mathrm{~mm}$ diameter bars were

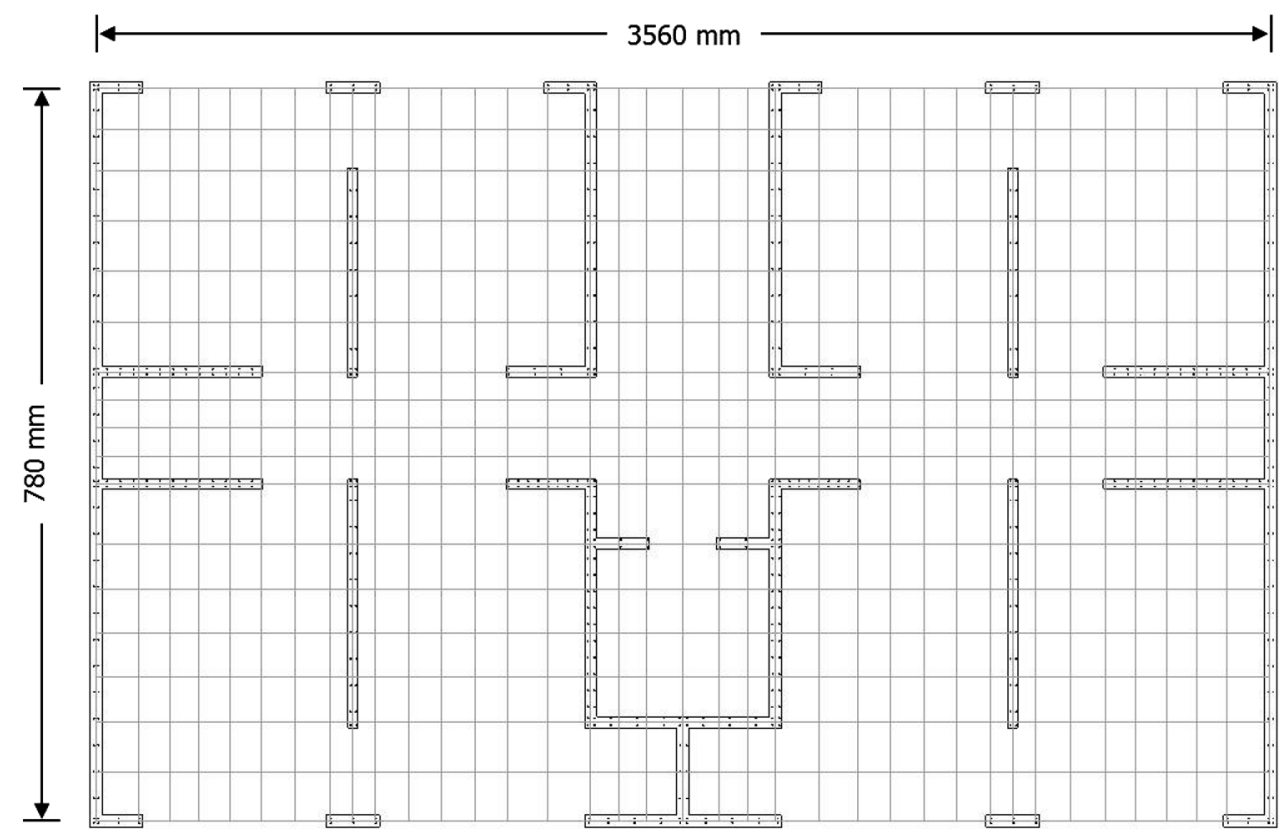

Fig. 12 Shell element grid for slabs in 3-D wall building. 

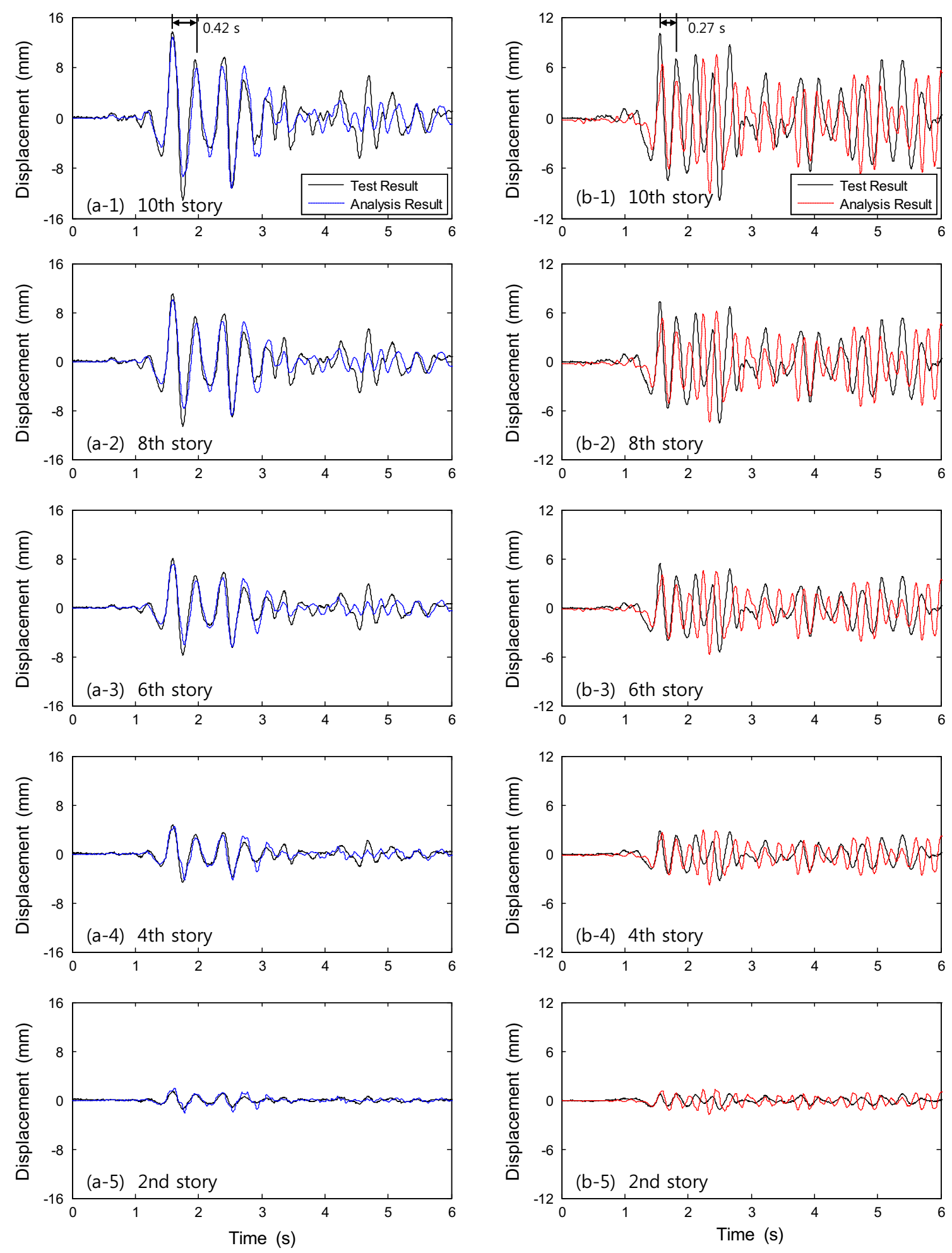

(a)

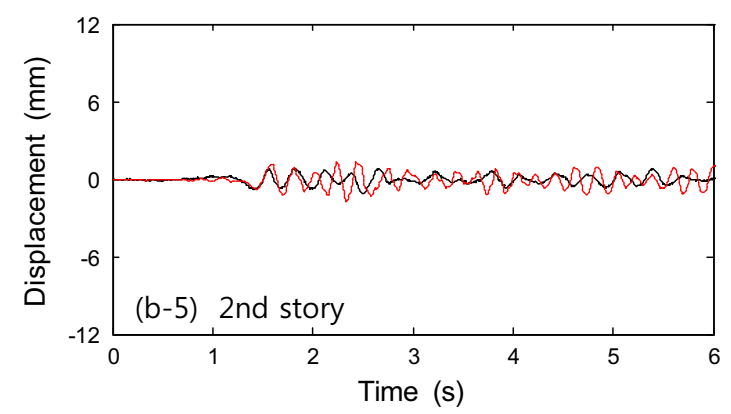

(b)

Fig. 13 Displacement of each story in 3-D wall building. a X-direction, b Y-direction.

used for the vertical bars, and $2 \mathrm{~mm}$ diameter bars were used for the horizontal bars. For slabs, $2 \mathrm{~mm}$ diameter bars were used.

Taft earthquake acceleration (N69E, S21E) was applied to the shaking table in the $\mathrm{x}$ and $\mathrm{y}$-directions, simultaneously. The peak input acceleration levels of the earthquake events were gradually increased from 0.07 to $0.525 \mathrm{~g}$. In the present study, test results of the peak ground acceleration (PGA) of
$0.374 \mathrm{~g}$, which was close to the design acceleration for site class $\mathrm{S}_{\mathrm{C}}$ in Korea Building Code, were used to compare the shaking table test and the numerical analysis result.

The dynamic periods of the 1:5 scale specimen were evaluated by the white noise input and the FFT analysis. Before the earthquake test, the dynamic periods in the $\mathrm{x}$ and y-directions were 0.24 and $0.18 \mathrm{~s}$, respectively. During the earthquake of $0.374 \mathrm{~g}$, the dynamic periods in the $\mathrm{x}$ and 


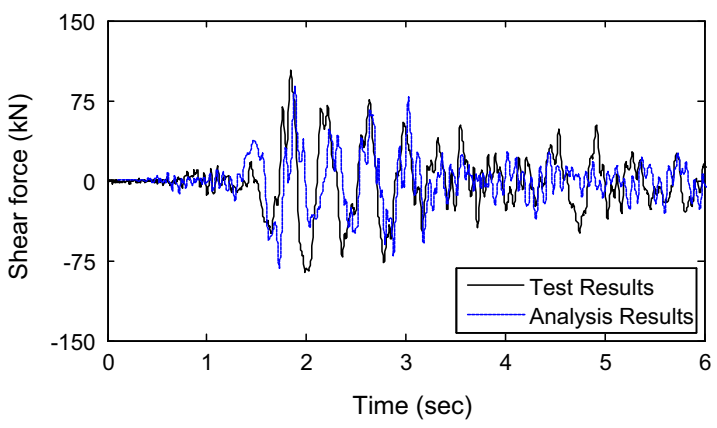

(a)

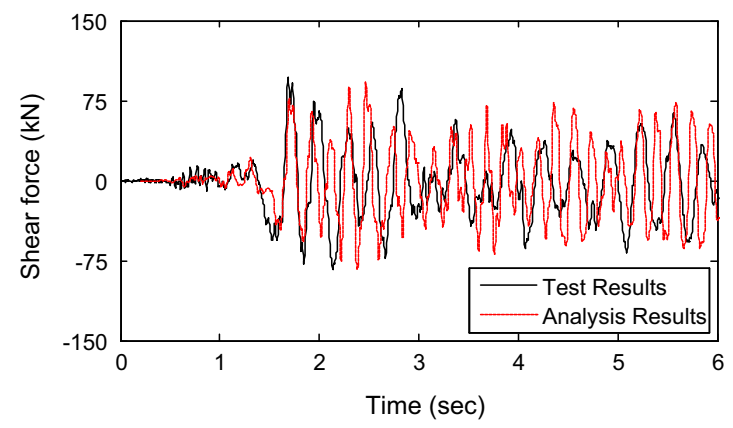

(b)

Fig. 14 Base shear of 3-D wall building. a X-direction, b Y-direction.

$\mathrm{y}$-directions were increased to 0.40 and $0.30 \mathrm{~s}$ due to structural damages of the specimen.

Figure 10b shows scheme of the nonlinear numerical analysis model for the R.C. wall specimen. To describe the proposed macro-model, out-of-plane bending of the wall, and effect of the slab, the truss element, the elastic beamcolumn element, and the shell element of the OpenSEES (PEER 2001) were used, respectively. Nonlinear materials of the OpenSEES, Concrete07 and Steel02, were used for the longitudinal and diagonal uniaxial elements of the macroelement.

Figure 11 presents a unit model for the three-dimensional behavior of a wall, and the contribution of each component to the six-degrees of freedom. For in-plan-action of the wall, the proposed macro-model using vertical and diagonal trusses was used, horizontal rigid beams were used. For outof-plane bending of the wall, vertical flexural element was used. As shown in Fig. 12, the slab was divided into $37 \times 18$ grid. Shell elements were used to describe the sixdegrees of freedom of the slab.

The out-of-plane flexural stiffness of the wall and the flexural stiffness of the slab should be considered as cracked sections. Considering translation of the neutral axis, $15 \%$ of the gross flexural stiffness $\left(=0.5 I_{g x}\right)$ was used for the out-ofplane flexural stiffness of the wall, and $20 \%$ of the gross flexural stiffness was used for the slab (shell element). From the eigenvalues of the analysis model, the Rayleigh damping of $5 \%$ was applied to the analysis model.

Figure 13 shows the net displacements of each story excluding the foundation displacement. In the $\mathrm{x}$-direction (Fig. 13a), the results of the analysis model were similar to those of the shaking table test. The dynamic period of the analysis model was $0.42 \mathrm{~s}$ which was close to that of the test specimen $(=0.40 \mathrm{~s})$.

In the y-direction (Fig. 13b), the period of the analysis model was $0.26 \mathrm{~s}$ which was smaller than that of the test specimen $(=0.30 \mathrm{~s})$. For this reason the displacements of the numerical analysis were smaller than those of the test specimen. This result indicates that the damages of the walls in the y-direction were not well predicted by the numerical analysis.

In Fig. 14, the base shear forces of the shaking table test and the numerical analysis were compared. The base shear force in the $\mathrm{x}$-direction was well predicted by the analysis model. For the y-direction, the base shear force predicted by the numerical analysis model was similar to that of the shaking table test.

\section{Summary and Conclusions}

In the present study, a macro-model for the nonlinear analysis of wall structures was developed. For convenience in modeling and numerical computation, the macro-model is idealized with longitudinal and diagonal uniaxial elements of concrete and re-bar. The proposed model is similar to the truss model that is popular in the design of reinforced concrete members. The proposed model was intended to describe both the flexure-compression and the shear responses, with reasonable precision. Particularly, the proposed model focused on accurate prediction of the shear response of walls associated with inclined cracking and diagonal strut action of the web concrete. The longitudinal and diagonal uniaxial elements consist of concrete and re-bar. Simplified cyclic models for the concrete and re-bar were used.

For verification, the proposed macro-model was applied to isolated wall specimens and a coupled wall specimen subjected to cyclic loading. The results showed that the proposed macro-model predicted well the flexure-compression and shear responses of the slender, short, and coupled walls, addressing the effects of various design parameters (e.g. shear span-to-depth ratio, axial compression force, reinforcement ratio, and the shape of cross sections). The characteristics of cyclic responses including strength- and stiffness-degradations, pinching behavior, and the overall shape of cyclic curves were reasonably captured.

Further, the proposed macro-model was applied to threedimensional nonlinear time history analyses for a 1:5 scale 10-story R.C. wall-type residential building specimen, which was tested on shaking table. The predictions were compared with the shaking table test results. The results showed that the displacements, the base shear forces, and the global deformation correlated well with the shaking test results.

However, the following limitations should be considered when the proposed macro-model is used: 1) the macromodel should not be used for walls subjected to very high axial compression load; 2) The walls should have sufficient shear reinforcement to resist in-plane shear. 


\section{Acknowledgments}

This work was supported by the National Research Foundation of Korea (NRF) grant (2010-0027593) funded by the Korean government's Ministry of Education, Science and Technology.

\section{Open Access}

This article is distributed under the terms of the Creative Commons Attribution 4.0 International License (http://creativecommons.org/licenses/by/4.0/), which permits unrestricted use, distribution, and reproduction in any medium, provided you give appropriate credit to the original author(s) and the source, provide a link to the Creative Commons license, and indicate if changes were made.

\section{References}

American Society of Civil Engineers (ASCE). (2000). Prestandard and commentary for the seismic rehabilitation of buildings. Reston, VA: FEMA-356.

American Society of Civil Engineers (ASCE). (2005). Improvement of nonlinear static seismic analysis Procedures. Reston, VA: FEMA-440.

Applied Technology Council (ATC). (1996). Seismic evaluation and retrofit of concrete buildings. Rep. No. ATC-40, Redwood City, CA.

Bentz, E. C., Vecchio, F. J., \& Collins, M. P. (2006). Simplified modified compression field theory for calculating shear strength of reinforced concrete elements. ACI Structural Journal, 103(4), 614-624.

Chang, G. A., \& Mander, J. B. (1994). Seismic Energy Based Fatigue Damage Analysis of Bridge Columns: Part I-Evaluation of Seismic Capacity. Rep. No. NCEER-940006, State University of New York at Buffalo, New York, NY.

Computer and Structures Inc. (2006). Nonlinear analysis and performance assessment for 3D structures, Berkeley, CA: Computer and Structures Inc.

D’Ambrisi, A., \& Filippou, F. C. (1999). Modeling of cyclic shear behavior in RC members. ASCE Journal of Structural Engineering, 125(10), 1143-1150.

Feenstra, P. H., \& de Borst, R. (1993). Aspects of robust computational modeling for plain and reinforced concrete. Heron, 38(4), 5-26.

Hsu, T. T. C., \& Mo, Y. L. (1985). Softening of concrete in lowrise shear walls. ACI Structural Journal, 82(6), 883-889.

Kabeyasawa, T., Shiohara, T., Otani, S., \& Aoyama, H. (1982). Analysis of the full-scale seven story reinforced concrete test structure: Test PSD3. In 3rd JTCC, US.-Japan Cooperative Earthquake Research Program, BRI, Tsukuba, Japan.

Lee, S. H., Hwang, S. J., Lee, K. B., Kang, C. B., Lee, S. H., \& Oh, S. H. (2011). Earthquake simulation tests on a 1:5 scale 10-story R.C. residential building model. Earthquake Engineering Society of Korea, 15(6), 67-80.
Lee, S. H., Oh, S. H., Hwang, W. T., Lee, K. B., \& Lee, H. S. (2010). Static experiment for the seismic performance of a 2 story RC shear wall system. Earthquake Engineering Society of Korea, 14(6), 55-65.

Linda, P., \& Bachmann, H. (1994). Dynamic modeling and design of earthquake-resistant walls. Earthquake Engineering and Structural Dynamics, 23, 1331-1350.

Mander, J. B., Priestley, M. J. N., \& Park, R. (1988). Theoretical stress-strain model for confined concrete. ASCE Journal of Structural Engineering, 114(8), 1804-1826.

Mansour, M. Y., \& Hsu, T. T. C. (2005). Behavior of reinforced concrete elements under cyclic shear. II: Theoretical model. ASCE. Journal of Structural Engineering, 131(1), 54-65.

Massone, L. M., Orakcal, K., \& Wallace, J. W. (2009). Modeling of squat structural walls controlled by shear. $A C I$ Structural Journal, 106(5), 646-655.

Massone, L. M., \& Wallace, J. W. (2009). RC wall shearflexure interaction: Analytical and experimental responses. Los Angeles, CA: College of Engineering, University of California (UCLA-SGEL-2009/2).

Menegotto, M., \& Pinto, P. E. (1973). Method of analysis for cyclically loaded reinforced concrete plane frames including changes in geometry and non-elastic behavior of elements under combined normal force and bending. In IABSE symposium on the resistance and ultimate deformability of structures acted on by well-defined repeated loads, Lisbon.

Monti, G., \& Spacone, E. (2000). Reinforced concrete fiber beam column element with bond slip. ASCE Journal of Structural Engineering, 126(6), 654-661.

Oesterle, R. G., Aristijabal-Ochoa, J. D., Shiu, K. N., \& Corley, W. G. (1984). Web crushing of reinforced concrete structural walls. ACI Structural Journal, 81(3), 231-241.

Okamura, H., \& Maekawa, K. (1991). Nonlinear analysis and constitutive models of reinforced concrete. Tokyo, Japan: Gihodo-Shuppan.

Orakcal, K. (2004). Nonlinear modeling and analysis of slender reinforced concrete walls. Dissertation, University of California, Los Angeles, CA.

Orakcal, K., Massone, L. M., \& Wallace, J. W. (2006). Analytical modeling of reinforced concrete walls for predicting flexural and coupled-shear-flexural responses. PEER Report 2006/07. Pacific Earthquake Engineering Research Center, University of California, Berkeley, CA.

Pacific Earthquake Engineering Research Center (PEER). (2001). Open system for earthquake engineering simulation. Berkeley, CA: University of California at Berkeley.

Palermo, D., \& Vecchio, F. J. (2007). Simulation of cyclically loaded concrete structures based on the finite-element method. ASCE Journal of Structural Engineering, 133(5), 728-738.

Park, H., \& Eom, T. (2007). Truss model for nonlinear analysis of RC members subject to cyclic loading. ASCE Journal of Structural Engineering, 133(10), 1351-1363.

Park, H., \& Klingner, R. E. (1997). Nonlinear analysis of RC members using plasticity with multiple failure criteria. ASEC Journal of Structural Engineering, 123(5), 643-651.

Petrangeli, M., Pinto, P. E., \& Ciampi, V. (1999). Fiber element for cyclic bending and shear of RC structures-I: Theory. 
ASCE Journal of Engineering Mechanics, 125(9), 994-1001.

Prakash, V., Powell, G. H., \& Campbell, S. (1993). DRAIN2DX Base Program Description and User Guide-Version 1.10. Rep. No. UCB/SEMM-93/17, Proceedings, Structural Engineering Mechanics and Materials, University of California, Berkeley, CA.

Salonikios, T. N., Kappos, A. J., Tegos, I. A., \& Penelis, G. G. (1999). Cyclic load behavior of low-slenderness reinforced concrete walls: Design basis and test results. ACI Structural Journal, 96(4), 649-660.

Salonikios, T. N., Kappos, A. J., Tegos, I. A., \& Penelis, G. G. (2000). Cyclic load behavior of low-slenderness reinforced concrete walls: Failure modes, strength and deformation analysis, and design implications. ACI Structural Journal, 97(1), 132-142.

Sittipunt, C., Wood, L. S., Lukkunaprasit, P., \& Pattararattanakul, P. (2001). Cyclic behavior of reinforced concrete structural walls with diagonal web reinforcement. $A C I$ Structural Journal, 98(4), 554-562.

Stevens, N. J., Uzumeri, S. M., Collins, M. P., \& Will, G. T. (1991). Reinforced concrete subjected to reversed cyclic shear-experiments and constitutive model. ACI Structural Journal, 88(2), 135-146.

Thomsen, J. H., \& Wallace, J. W. (2004). Displacement-based design of slender reinforced concrete structural wallsExperimental verification. ASCE Journal of Structural Engineering, 130(4), 618-630.

Vecchino, F., \& Collins, M. P. (1986). The modified compression field theory for reinforced concrete elements subject to shear. ACI Structural Journal, 83(2), 219-231.

Vulcano, A., \& Bertero, V. (1987). Analytical model for predicating the lateral response of RC shear walls: Evaluation of their reliability. Report No. UCB/EERC-87/19, USA.

Wallace, J. W. (2012). Behavior, design, and modeling of structural walls and coupling beams-Lessons from recent laboratory tests and earthquakes. International Journal of Concrete Structures and Materials, 6(1), 3-18.

Wong, P. S., \& Vecchio, F. J. (2002). VecTor2 \& Formworks User's Manuals. Toronto, Canada: Department of Civil Engineering, University of Toronto, Canada.

Zhang, L. X., \& Hsu, T. T. C. (1998). Behavior and analysis of $100 \mathrm{MPa}$ concrete membrane elements. ASCE Journal of Structural Engineering, 124(1), 24-34. 